\title{
PENGARUH MODEL LEARNING CYCLE TERHADAP HASIL BELAJAR PADA MATERI PENCEMARAN LINGKUNGAN SISWA KELAS VII DI SMP NEGERI 15 AMBON
}

\author{
Astrid Rhita Jacob ${ }^{1}$ dan Alwi Smith ${ }^{2}$ \\ ${ }^{1}$ Alumni Program Studi Pendidikan Biologi, FKIP Universistas Pattimura \\ ${ }^{2}$ Staf Pengajar Program Studi Pendidikan Biologi, FKIP Universitas Pattimura
}

\begin{abstract}
Background: Education that is used as a forum to develop human potential requires a clear and mature set of systems to be able to deliver people to their potential development. For this reason, development in the education sector must continue to be developed in the direction of improving the quality of education.

Method: This study was conducted at SMP Negeri 15 Ambon with a total of 25 students in class VIII. The KKM of SMP 15 Ambon biology subjects is 70 . This study uses descriptive analysis to determine the learning outcomes of cognitive, affective, and psychomotor students.

Results: Research shows that mastery of biological concepts before the application of the learning cycle model is classified as very low. This can be seen from the average score of achievement in the initial test, which is 40 from KKM. After the application of the learning cycle learning method, the formative test results obtained by students became better with the average percentage of achievement in the formative test increasing by 89 .

Conclusion: Learning cycle learning method is able to improve student learning outcomes on the concept of environmental pollution.
\end{abstract}

Keywords: Learning Cycle Learning Model, Learning Outcomes,

\begin{abstract}
Abstrak
Latar Belakang: Pendidikan yang digunakan sebagai wadah untuk mengembangkan potensi manusia memerlukan seperangkat sistem yang jelas dan matang agar mampu mengantarkan manusia dalam pengembangan potensinya. Untuk itu, pembangunan pada bidang pendidikan harus terus dikembangkan ke arah peningkatan mutu Pendidikan.

Metode: Penelitian ini dilaksanakan pada SMP Negeri 15 Ambon dengan jumlah siswa kelas $\mathrm{VII}^{8}$ sebanyak 25 orang. Adapun KKM mata pelajaran biologi SMP 15 Ambon adalah 70. Penelitian ini menggunakan analisis deskriptif untuk mengetahui hasil belajar kognitif, afektif, dan psikomotor siswa. Hasil: Penelitian menunjukkan bahwa penguasaan konsep biologi sebelum penerapan model pembelajaran learning cycle tergolong sangat rendah. Hal ini terlihat dari nilai rata-rata pencapaian pada tes awal yaitu 40 dari KKM. Setelah penerapan metode pembelajaran learning cycle, hasil tes formatif yang diperoleh siswa menjadi lebih baik dengan prosentase rata-rata pencapaian pada tes formatif meningkat sebesar 89.

Kesimpulan: Metode pembelajaran learning cycle mampu meningkatkan hasil belajar siswa pada konsep pencemaran lingkungan
\end{abstract}

Kata Kunci: Model pembelajaran learning cycle, hasil belajar, 


\section{PENDAHULUAN}

Pendidikan yang digunakan sebagai wadah untuk mengembangkan potensi manusia memerlukan seperangkat sistem yang jelas dan matang agar mampu mengantarkan manusia dalam pengembangan potensinya. Untuk itu, pembangunan pada bidang pendidikan harus terus dikembangkan kearah peningkatan mutu Pendidikan (Arnyana, 2006). Pendidikan di Indonesia sendiri sudah memiliki suatu sistem yaitu kurikulum yang didalamnya memiliki struktur kurikulum pada setiap jenjangnya. Salah satu unsur pendidikan adalah adanya guru, siswa, kurikulum, bahan ajar, interaksi dan hasil belajar (Ismail, 2013). Pemahaman merupakan salah satu aspek yang perlu diperhatikan dalam suatu pembelajaran karena puncak dari pembelajaran adalah hasil belajar (Sastrika, 2013). Belajar tidak hanya meliputih mata pelajaran, tetapi juga penguasaan, kebiasaan, persepsi, kesenangan, kompetensi, penyesuaian social, bermacam-macam ketrampilan dan cita-cita (Morgan, 2009).

Pada proses pembelajaran, siswa dan guru memainkan peran yang terdefinisi dengan baik, dimana siswa diberi peran utama menjadi yang lebih aktif dan guru berperan sebagai organisator, pembimbing dan fasilitator. Salah satu pendekatan pembelajaran konstruktivisme yang dapat diterapkan dalam proses pembelajaran oleh guru sehingga dapat meningkatkan hasil belajar siswa adalah model pembelajaran learning cycle " $5 e$ ".

Learning cycle atau siklus belajar adalah suatu model pembelajaran yang berpusat pada siswa yang merupakan rangkaian tahap-tahap kegiatan (fase) yang diorganisasi sedemikian rupa sehingga siswa dapat menguasai kompetensikompetensi yang harus dicapai dalam pembelajaran dengan berperan aktif. Rancangan model pembelajaran learning cycle "5e" ini memiliki langkah- langkah pembelajaran yang dapat berimplikasi meningkatkan hasil belajar siswa. Sudjana (2005) menyatakan bahwa, "hasil belajar siswa pada hakikatnya adalah perubahan tingkah laku lebih lanjut, dikatakan bahwa hasil belajar adalah kemampuankemampuan yang dimiliki siswa setelah menerima pengalaman belajarnya"
Model pembelajaran learning cycle dapat diterapkan pada materi pencemaran lingkungan, dengan model tersebut diharapkan dapat membuat siswa dengan mudah memahami materi karena memadukan antara teori yang disampaikan dengan kenyataan yang ada di lapangan dengan secara langsung belajar mengidentifikasi berbagai pencemaran yang ada di lingkungan sekitar. Siswa belajar bukan hanya utnuk mengetahui, tetapi belajar untuk mengalami apa yang dipelajarinya.

Berdasarkan hasil observasi yang dilakukan antara siswa dan guru di SMP Negeri 15 Ambon, masih banyak siswa yang mengalami kesulitan belajar. Mereka mengalami kesulitan ketika mengaitkan konsep dengan masalah yang ada dalam kehidupan sehari-hari, khususnya pada konsep pencemaran lingkungan kebanyakan siswa belajar dengan cara menghafal materi bukan dengan cara memahaminya. Siswa juga masih kesulitan ketika diminta untuk memberikan alternatif contoh aplikasi konsep yang ada dilingkungan. Siswa kurang mampu mengkomunikasikan pendapatnya dalam diskusi.

Untuk mengembangkan pembelajaran IPA, guru dituntut merancang dan melaksanakan eksperimen IPA yang mendukung pembelajaran. Dalam hal ini, guru perlu menggunakan model pembelajaran dan sumber belajar yang relevan untuk mencapai tujuan pembelajaran secara utuh. Salah satu model pembelajaran yang dapat digunakan untuk mendukung proses pembelajaran adalah model learning cycle. Hal ini karena model learning cycle adalah model yang menekankan pada proses pencarian pengetahuan dari pada transfer pengetahuan. Hal ini karena model learning cycle adalah model yang menekankan pada proses pencarian pengetahuan dari pada transfer pengetahuan. Siswa dipandang sebagai subjek belajar yang perlu dilibatkan secara aktif dalam proses pembelajaran dan guru hanyalah seorang fasilitator yang membimbing serta mengkoordinasikan kegiatan belajar siswa. 


\section{MATERIAL DAN METODE}

Jenis penelitian yang digunakan dalam penelitian ini adalah penelitian deskriptif untuk meningkatkan hasil belajar siswa dengan penerapan metode pembelajaran Learning Cycle terhadap hasil belajar siswa pada materi pencemaran lingkungan kelas VII di SMP N 15 AMBON.

Penilitian ini di lakukan pada Smp negeri 15 ambon Penelitian ini dilaksanakan mulai dari tanggal 14 September sampai 14 Oktober.Populasi dalam Penelitian adalah seluruh kelas VII SMP N 15 Ambon yang berjumlah delapan kelasVariabel Bebas: yang menjadi variabel bebas dalam penelitian ini adalah Yaitu pengaruh model pembelajaran Learning Cycle.

Variabel Terikat yang menjadi variabel terikat dalam penelitian ini Yaitu hasil belajar biologi pada sistem pencemaran lingkungan. Data dalam penelitian ini kemudian diolah menggunakan analisis statistic deskriptif:

1. Hasil Belajar diperoleh dari hasil tes formatif, skor pencapaian diperoleh

Aspek kognitif menggunakan rumus : skor pencapaian $=\frac{\text { Skor perolehan }}{\text { Skor maksimum }} \times 100$

2. Aspek kognitif diperoleh dari lembar kerja siswa (LKS) dengan nilai formatif.

Proses penilaian aspek kognitif pada

LKS dengan menggunakan rumus : skorpencapaian $=\frac{\text { Skor perolehan }}{\text { Skor maksimum }} \times 100$

3. Untuk hasil observasi (aspek afektif dan psikomotor), skor pencapaian diperoleh dengan : skorpencapaian $=\frac{\text { Skor perolehan }}{\text { Skor maksimum }} \times 100$

Selanjutnya, untuk nilai proses (NP) diperoleh dengan cara:

$N P$

$=\frac{\text { P. kognitif }+ \text { P. afektif }+ \text { P. psikomotor }}{3} \times 100$

Data yang terkumpul dianalisa untuk memperoleh nilai akhir (NA).

Nilai tes formatif $(F)$ : Bobot penilaian dari keduanya adalah $\mathrm{P}=6$ dan $\mathrm{F}=4$.

$\mathrm{Na}=\frac{6 \mathrm{P}+4 \mathrm{~F}}{10}$

Nilai akhir ditentukan dengan rumus:

Keterangan:

NA : Nilai Akhir

$P$ :Nilai proses yang di peroleh dari nilai kognitif LKS, afektif dan pisikomotor.

$F$ : Nilai formatif setelah proses pembelajaran.

Selanjutnya Nilai Akhir (NA) Yang menggambarkan tingkat penguasaan minimum. Pada nilai akhir (NA) yang menggambarkan tingkat penguasaan individual terhadap konsep menghargai keputusan bersama dari segi hasil maupun proses (Arikunto, 2006).

\section{HASIL DAN PEMBAHASAN Tes awal (pre-test)}

Hasil dari penilitian ini berupa hasil belajar siswa menggunakan penerapan model pembelajaran Learning Cycle pada materi pencemaran lingkungan.

Tabel 1. Kualifikasi Skor Pencapaian Siswa Pada Tes Awal

\begin{tabular}{cccc}
\hline Interval & Frekuensi & Presentase (\%) & Kualifikasi \\
\hline $85-100$ & 0 & 0 & Sangat Baik \\
$77-84$ & 3 & 12 & Baik \\
$70-76$ & 1 & 4 & Cukup \\
$50-69$ & 3 & 12 & Kurang Baik \\
$\leq 49$ & 18 & 72 & Gagal \\
Jumlah & 25 & $100 \%$ & \\
\hline
\end{tabular}

Hasil kemampun awal siswa sebelum melakukan proses pembelajaran yaitu pada interval terdapat 3 siswa dengan presentase $(12 \%)$ berada pada kualifikasi baik dan 1 siswa dengan presentase (4\%) berada pada kualifikasi cukup dan 3 siswa dengan presentase (12\%) berada pada kualifikasi kurang dan 18 siswa dengan presentase $(72 \%)$ berada pada kualifikasi gagal dengan skor maksimum yang diperoleh oleh siswa yaitu dari KKM yang telah ditetapkan yaitu 70 . Hal ini membuktikan bahwa pemahaman atau 
penguasaan konsep pencemaran lingkungan masih tergolong rendah

Hal ini membuktikan bahwa belum ada keberhasilan pada tes awal, dimana siswa pada awal proses pembelajaran belum memiliki konsep dasar tentang pencemaran lingkungan. Hal ini sejalan dengan pemahaman Ridwan (2006) tes adalah serangkaian pertanyaan yang digunakan untuk mengukur keterampilan, pengetahuan, intelegensi, kemampuan atau bakat yang dimiliki individu atau kelompok.

\section{Deskrisi Penilaian Siswa Selama Proses Belajar Mengajar}

Dalam proses belajar membelajaran dengan menggunakan metode pembelajaran Learning Cycle diperlukan tiga aspek untuk menilai hasil belajar selama proses belajar mengajar yakni aspek kognitif, aspek afektif, dan aspek psikomotor.

\section{Hasil Penilaian Aspek Kognitif}

Berdasarkan hasil penilitian yang dilakukan pada Smp Negeri 15 Ambon, kemampuan kognitif yang siswa dalam proses pembelajran hal ini siswa mengerjakan lembaran kerja siswa (LKS) yang digunakan untuk melihat hasil kerja siswa dikelas. Hasilnya dapat dilihat pada table

Tabel 2. Kualifikasi Penilaian Rata-Rata Hasil Kognitif

\begin{tabular}{cccc}
\hline Interval & Frekuensi & Presentase (\%) & Kualifikasi \\
\hline $85-100$ & 16 & 64 & Sangat Baik \\
$77-84$ & 9 & 36 & Baik \\
$70-76$ & - & - & Cukup \\
$50-69$ & - & - & Kurang Baik \\
$\leq 49$ & - & - & Gagal \\
Jumlah & 25 & 100 & \\
\hline
\end{tabular}

Berdasarkan Tabel 2 diatas diketahui bahwa 16 siswa dengan presentase (64\%) memperoleh nilai (85-100) dengan keterangan sangat baik, dan 9 siswa dengan presentase $(36 \%)$ memperoleh nilai (77-84) dengan keterangan baik.

Proses ini menunjukan bahwa metode pembelajaran Learning Cycle memiliki langkah-langkah pembelajaran yang mampu mendorong siswa dalam proses belajar. Hal ini sejalan dengan pendapat Wenno (2008) yang menyatakan dalam kelompok dengan kemampuan yang heterogen, siswa belajar bersama dengan kelompok kecil yang membantu satu sama lain serta melatih siswa menerima perbedaan pendapat dan bekerja dengan teman yang berbeda latar belakangnya.

\section{Hasil Penilaian Aspek Afektif}

Data dari aspek afektif diperoleh melalui lembaran observasi yang digunakan untuk menilai kemampuan siswa yang meliputi: peran aktif siswa, kerja sama dalam kelompok, menghargai pendapat teman, dan memberikan kesempatan kepada teman yang lain dalam kelompok. Hasil dari aspek afektif dapt dilihat pada Tabel

Tabel 3. Kualifikasi Penilaian Rata-Rata Hasil Afektif

\begin{tabular}{cccc}
\hline Interval & Frekuensi & Presentase (\%) & Kualifikasi \\
\hline $85-100$ & 5 & $20 \%$ & Sangat Baik \\
$77-84$ & 20 & $80 \%$ & Baik \\
$70-76$ & - & - & Cukup \\
$50-69$ & - & - & Kurang Baik \\
$\leq 49$ & - & - & Gagal \\
Jumlah & 25 & 100 & \\
\hline
\end{tabular}


Pada aspek Afektif, terdapat 5 siswa dengan presentase (20\%) memperoleh nilai interval (85-100) yang berada pada kualifikasi sangat baik, 20 siswa sengan presentase $(80 \%)$ memperoleh nilai interval (77-84) yang berada pada kualifikasi baik.

Hal ini menyatakan bahwa siswa telah mengalami ketuntasan belajar. Hal ini sejalan menurut Sudjana (2009) tipe hasil belajar afektif berkenan dengan perasaan, minat dan perhatian, keinginan, ketika dihadapkan dengan objek tertentu.

\section{Hasil Penilaian Aspek Psikomotor}

Berdasarkan data dari hasil psikomotor dengan menggunakan proses belajar mengajar yang dinilai dari empat indikator yaitu melakukan langka-langka pada lembar kerja siswa (LKS), penilaian dari hasil percobaan, menyimpulkan hasil kerja, mempresentasikan hasil kerja kelompok. Hasil yang di peroleh dari aspek psikomotor dapat dilihat pada tabel 4 .

Tabel 4. Kualifikasi Penilaian Rata-Rata Hasil Psikomotor

\begin{tabular}{cccc}
\hline Interval & Frekuensi & Presentase (\%) & Kualifikasi \\
\hline $85-100$ & 11 & $44 \%$ & Sangat Baik \\
$77-84$ & 14 & $56 \%$ & Baik \\
$70-76$ & - & - & Cukup \\
$50-69$ & - & - & Kurang Baik \\
$\leq 49$ & - & - & Gagal \\
Jumlah & 25 & 100 & \\
\hline
\end{tabular}

Pada Tabel 4 menunjukan bahwa data yang diperoleh dari hasil penilaian psikomotor terdapat 11 siswa dengan presentase (44\%) memperoleh nilai interval (85-100) yang berada pada kualifikasi sangat baik, 14 siswa dengan presentase $(56 \%)$ memperoleh nilai interval $(77-84)$ yang berada pada kualifikasi baik.

Keberhasilan yang diperoleh siswa pada aspek psikomotor ini dikarenakan adanya keseriusan dan lebih bertanggung jawab dalam memecahkan dan menyelesaikan setiap tugas-tugas yang diberikan. Hal ini menunjukan bahwa penggunaan metode pembelajaran Learning Cycle sangat membantu siswa dalam ketuntasan belajar pada aspek psikomotor.

\section{Hasil Tes Formatif (Tes Akhir)}

Kualifikasi presentasi pencapaian siswa pada tes formatif yang dilakukan setelah proses kegiatan belajar mengajar (KBM) dengan penerapan metode pembelajran Learning Cycledi.

Tabel 5. Kualifikasi Hasil Tes Akhir

\begin{tabular}{cccc}
\hline Interval & Frekuensi & Presentase (\%) & Kualifikasi \\
\hline $85-100$ & 15 & $60 \%$ & Sangat Baik \\
$77-84$ & 10 & $40 \%$ & Baik \\
$70-76$ & - & - & Cukup \\
$50-69$ & - & - & Kurang Baik \\
$\leq 49$ & - & - & Gagal \\
Jumlah & 25 & 100 & \\
\hline
\end{tabular}

Berdasarkan Tabel 5 terlihat bahwa 15 siswa $(60 \%)$ mampu menguasai indikator pembelajaran dengan kualifikasi sangat baik, 10 siswa (40\%) dengan kualifikasi baik. Hal ini sangat membuktikan bahwa setela proses belajar mengajar dilakukan dengan menggunakan penerpan metode Learning Cycle dengan konsep pencemaran lingkungan menjadi sangat baik. 
Nilai Akhir

Nilai akhir yang diperoleh siswa adalah dari nilai proses yang didapat dari hasil perhitungan nilai aspek kognitif, aspek afektif, dan aspek psikomotor. Dan presentase penguasaan siswa pada hasil tes (Tes Akhir). Nilai akhir yang diperoleh oleh masing-masing siswa berbeda-beda.

Tabel 6. Grafik Kualifikasi Nilai Akhir (NA)

\begin{tabular}{cccc}
\hline Interval & Frekuensi & Presentase (\%) & Kualifikasi \\
\hline $85-100$ & 15 & $60 \%$ & Sangat Baik \\
$77-84$ & 10 & $40 \%$ & Baik \\
$70-76$ & - & - & Cukup \\
$50-69$ & - & - & Kurang Baik \\
$\leq 49$ & - & - & Gagal \\
Jumlah & 25 & 100 & \\
\hline
\end{tabular}

Berdasarkan Tabel 6 menunjukan bahwa hasil akhir yang diperoleh adalah 15 siswa (60\%) dengan interval (85-100) berada pada kualifikasi sangat baik, 10 siswa $(40 \%)$ dengan interval baik. Dari hasil yang diperoleh menunjukan bahwa tingkat penguasaan materi oleh siswa melewati kriteria ketuntasan KKM yaitu 70.

Hasil penelitian menunjukan bahwa hasil belajar siswa dengan menggunakan metode pembelajaran learning cycle, memberikan pengaruh yang baik terhadap hasil belajar konsep pencemaran lingkungan. Hal ini dapat terjadi karena menggunakan metode learning cycle adapun fase-fase sebagai berikut: fase pertama guru menyampaikan tujuan dan motivasi siswa, serta menyajikan informasi kepada siswa. Fase kedua guru menjelaskan materi keanekaragaman hayati setahap demi setahap. Setelah itu siswa dibentuk dalam kelompok-kelompok belajar dan diberikan soal-soal latihan berupa lembar kerja siswa (LKS) yang dikerjakan secara bersama-sama dengan tujuan agar siswa dapat mengerti materi yang diajarkan karena semakin banyak soal-soal latihan yang diberikan maka dapat membantu siswa untuk lebih memahami materi. Tujuan LKS dalam kelompok agar siswa belajar untuk berusaha menyelesaikan soal-soal yang diberikan secara bersama-sama dan mampu memberikan penjelasan tentang pemahaman materi kepada teman kelompoknya dalam hal saling

\section{KESIMPULAN}

Berdasarkan hasil penelitian dan pembahasan, maka dapat disimpulkan bahwa metode pembelajaran learning cycle mampu meningkatkan hasil belajar siswa konsep pencemaran lingkungan, hal ini terlihat dari : kemampuan awal seluruh suswa sebelum proses belajar mengajara (PBM) tidak mencapai KKM, dengan tes rata-rata tes awal adalah $40 \%$, dan setelah proseses pembelajaran dilakukan dengan penerapan metode pembelajaran Learning Cycle siswa dapat mencapai nilai KKM ini dibuktikan pada tes kemampuan akhir dengan perolehan nilai rata-rata mencapai $89 \%$.

\section{DAFTAR PUSTAKA}

Arikunto. 2006. Prosedur Penelitian Suatu Pendekatan Praktek. Jakarta : PT. Rineka Cipta.

Arnyana. 2006. Pengaruh Penggunaan Model Siklus Belajar Dalam Pembelajaran Biologi Terhadap Penguasaan Konsep, Penalaran, dan Keterampilan Inkuiri Siswa SMP Laboratorium. Laporan Penelitian. Dibiayai Dari Dana Daftar Isian Pelaksanaan.

Daryanto. 2010. Metodologi Penelitian Pendidikan. SIC. Surabaya.

Ismail, (2013). Pendidikan Kependudukan dan l.ingkungan hidup untuk IKIP dan FKIP. Jakarta: Depdikbud.Ruci.

Morgan, 2009. Obsteri \& Ginekologi. Jakarta: Rajawali Presss.

Ridwan, (2006). Aplikasi Statistika dan Metode Penelitian. Bandung: Dewa Ruci. 
Biopendix, Volume 0, Nomor 0, Oktober 2014, hlm, 00-00

Sastrika, 2013. Upaya menigkatkan Penerimaan diri dalam bergaul siswa melalui konseling kelompok dengan teknik Modeling Simbolik Kelas $X$ multimedia SMK Taman Siswa. Skripsi. Kudus UMK.

Sudjana, Nana. 2005. Dasar-dasar Proses Belajar Mengajar. Bandung: Sinar Baru Algensindo.
Sudjana, Nana 2008. Penilaian Hasil Proses Belajar Mengajar. Bandung: PT Remaja Rosdakarya Offset

Sudjana, Nana 2009. Penilaian Hasil Proses Belajar Mengajar. Bandung: PT Remaja Rosd Karya 